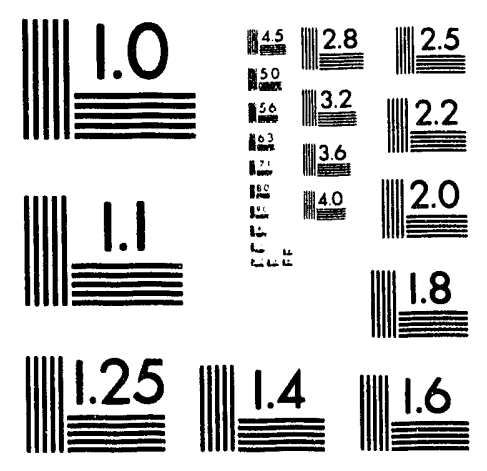



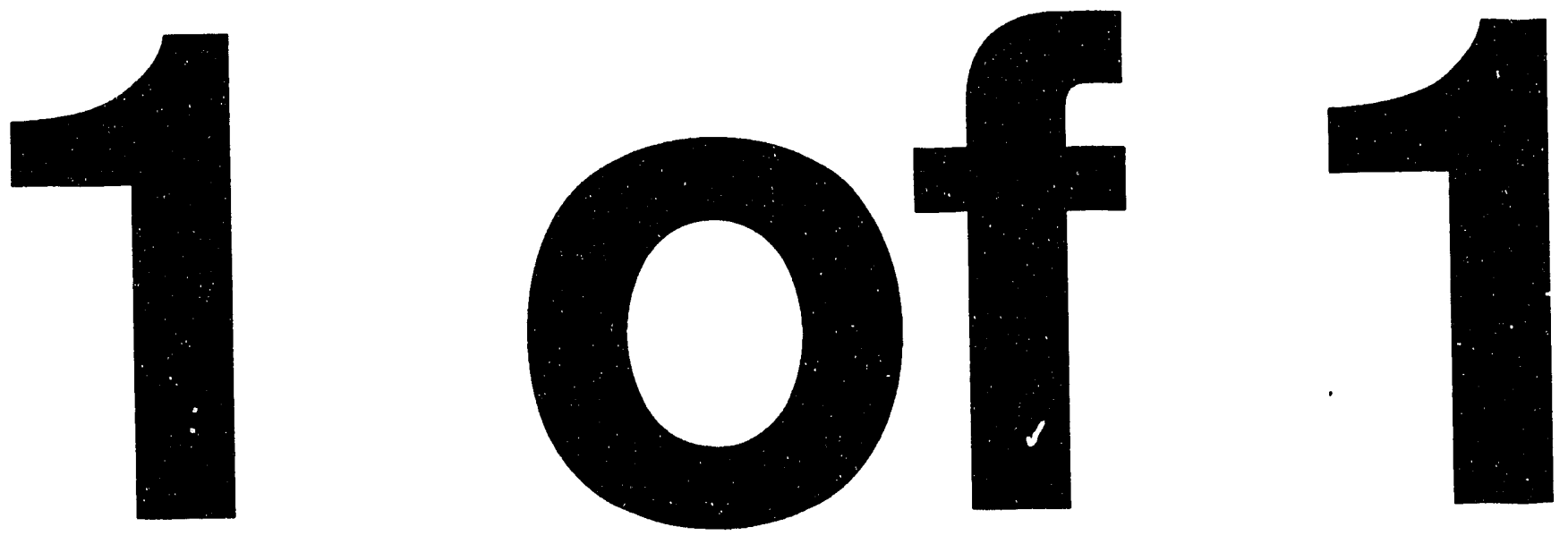


$$
\begin{array}{r} 
\\
\text { LBL/ISU/AGMus } \\
\text { Science Consortium } \\
\text { Annual Report } \\
\text { FY 1991-1992 }
\end{array}
$$

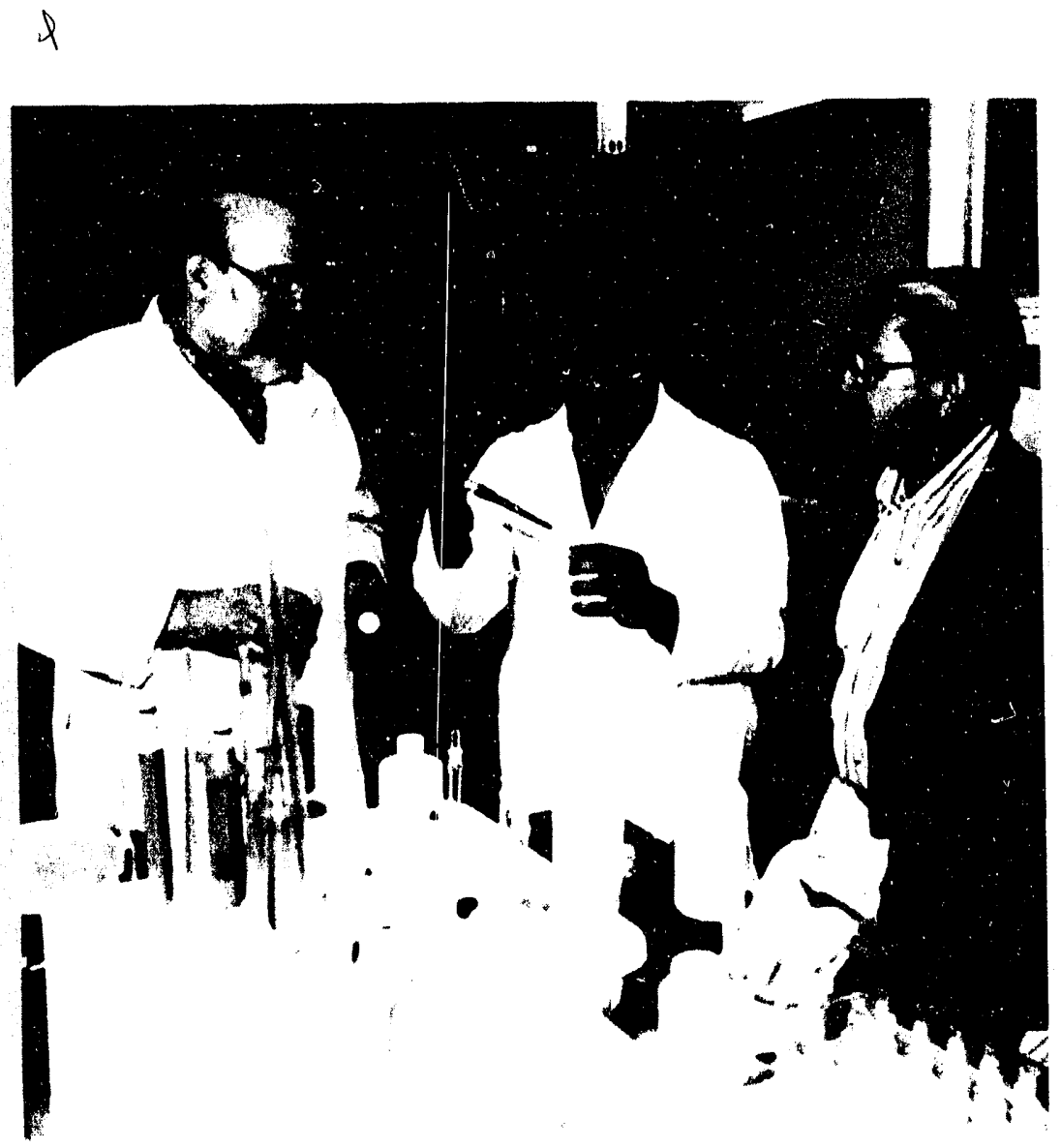

Lawrence Berkeley Laboratory Berkeley, Califomia Jackson State University Jackson, Mississippi Ana G. Méndez University System Río Piedras, Puerto Rico 


\section{On the Cover. . .}

Dale Perry (left) from Lawrence

Berkeley Laboratory's Earth Sciences

Division works with chemistry

professor Luis Feliú (right) and student Andrés Polanco, both from

Metropolitan University, to investigate the "Chemistry of Toxic

Organic/Metal lon Co-Cuntaminants and Their Effects on Microbial Communities." This is a collaborative research project to characterize metal-organic compounds that are present as hazardous contaminants in the environment.

The Lawrence Berkeley Laboratory/lackson State University/Ana G. Méndez University System Science Consortium is supported by the Office of Energy Research, U.S. Department of Energy.

The Lawrence Berkeley Laboratory is operated by the Regents of the University of California for the U.S. Department of Energy under contract 
B enefits of the long-term commitment to collaboration made by the partners in the Science Consortium became evident during FY 1991 and FY 1992. In the spring of 1992, the Ana G. Méndez University System dedicated a new building for scientific investigation on the campus of Metropolitan University. Members of the faculty actively involved in environmental and biological research were ready to move into the facility as soon as it was completed. Many of these faculty members received their start in research and development at Lawrence Berkeley Laboratory (LBL) and continue their work with LBL and Jackson State University scientists through collaborations supported by the Science Consortium. All of this seemed a remote goal more than eight years ago when LBL scientific staff traveled to Puerto Rico to consult on the design of the science laboratories.

Another benefit of the collaboration became apparent when Jackson State University established and received approval for a Ph.D. program in environmental science. The Science Consortium contributed to building Jackson State University's capacity to offer this degree through a number of successful collaborative research projects.

These past two years have been a time of significant expansion of precollege mathematics and science outreach activities at both Jackson State University and the Ana G. Méndez University System. Science Consortium planning and support for many of the pilot efforts and programs have contributed to leadership roles in outreach at these institutions.

The biggest return on investment has been the establishment of Bioremediation Education, Science and Technology Centers on the campuses of the University of California at Berkeley, Jackson State University, and Ana G. Méndez University System. These Centers will provide research, training, education, and leadership opportunities for underrepresented students and their faculty across the country in the emerging field of bioremediation of toxic metals and mixed waste.

The Science Consortium has continued during 1991 and 1992 to be a successful model of cooperation for ensuring hundreds of African American and Hispanic students access to, and opportunity for, graduate degrees and careers in the natural sciences, computer science, mathematics, and technology. Many other successes, some institutional and some very personal, are documented in this annual report.

\section{MASTER}

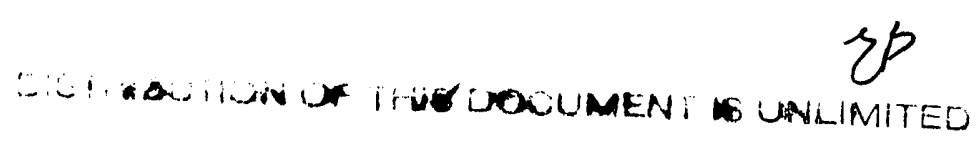




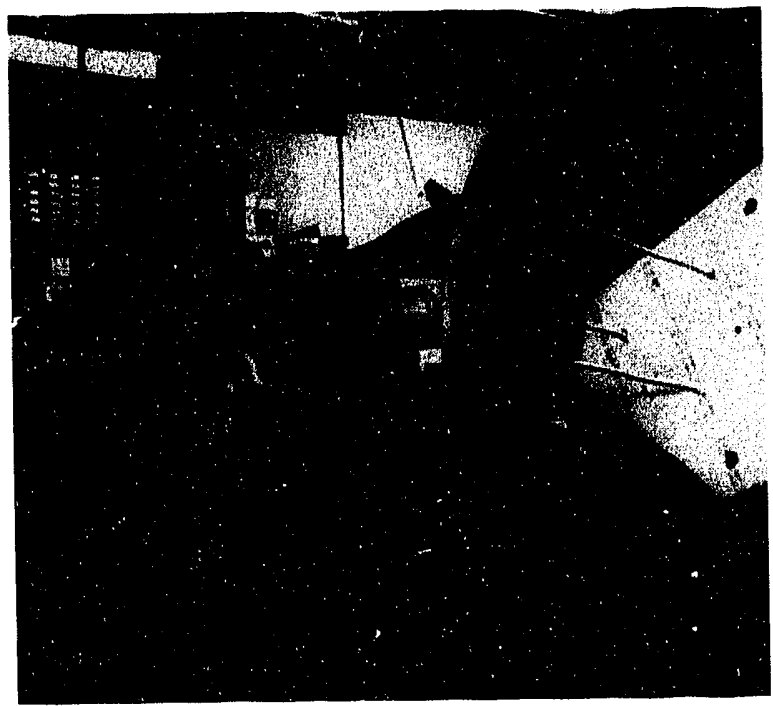

n 1983, a formal Memorandum of

Understanding joined the Ana G. Méndez University System (AGMUS), Jackson State University (JSU), and the Lawrence Berkeley Laboratory (LBL) in a consortium designed to advance the science and technology programs of JSU and AGMUS. This is the first such collaboration between a Hispanic university system, a historically Black university, and a national laboratory. The goals of this alliance are basic and direct: to develop and effect a long-term, comprehensive program that will enable the campuses of AGMUS and JSU to provide a broad, high-quality offering in the natural and computer sciences, to

Jackson State physics student Tracy Miller working on a remote control telescope at $L B L$. 


\section{INTRODUCTION}

increase the number of minority students entering these fields, and to contribute to scientific knowledge and the federal government's science mission through research.

The LBL/JSU/AGMUS Science Consortium has developed plans for utilizing its program successes to help other institutions to adopt or adapt those elements of our model that have produced the greatest results. Within the five-year plan formulated in 1990 are eight major components, each with defining elements and goals. These elements have become the components of the Science Consortium's current plan for expansion and propagation.

Students in computer lab at Jackson State.

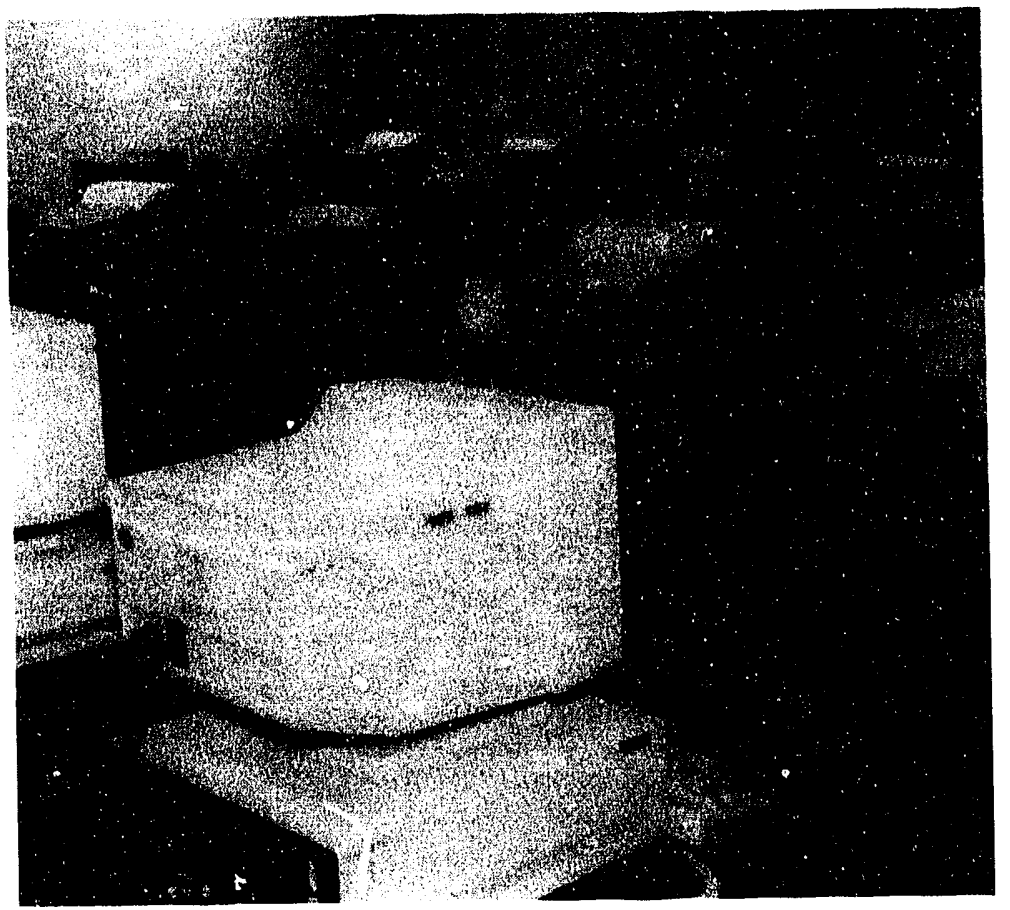

LBL is a multiprogram national laboratory managed by the University of California for the U.S. Department of Energy (DOE). The oldest of the nine national laboratories, LBL is the only one located immediately adjacent to one of the world's great universities, the Berkeley campus of the University of California (UCB). The Laboratory serves the nation and its scientific and educational communities through energy-related research performed in its unique facilities.
LBL has a four-part mission:

- To perform leading

multidisciplinary research in general sciences, energy sciences, and life sciences.

- To develop and operate unique national experimental facilities for use by qualified investigators.

- To educate and train future generations of scientists and engineers.

- To foster productive relationships between LBL research programs and industry. 
Current programs encompass all the natural sciences, as well as engineering, mathematics, and computer science. Basic studies of the nature of the atom and the cell, research on new trealments for cancer patients, and the development of advanced materials, instruments, facilities, and new energy sources are typical examples of LBBL research.

Jackson State University, a coeducational institution, was founded at Natchez, Mississippi, in November 1882 by the American Baptist Ilome Mission Society. It is presently located in Jackson, Mississippi. The University's mission is "to develop persons who can and will assume prominent roles in the dynamics of societal growth and

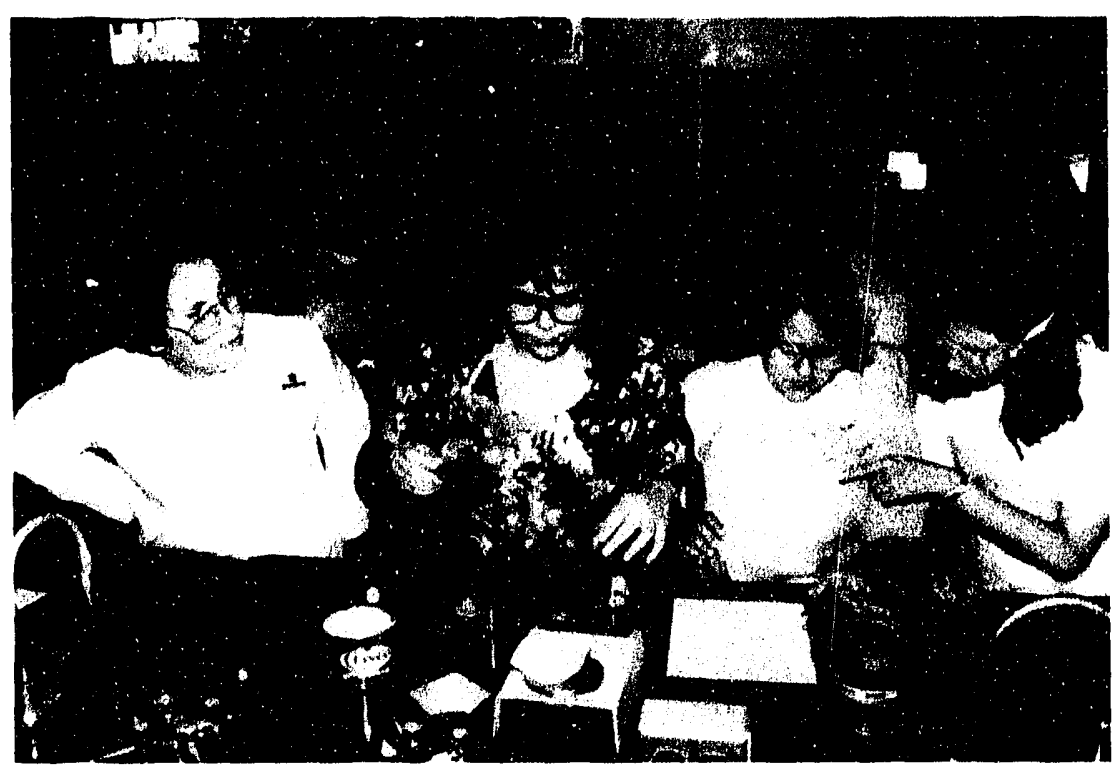

change." Programs are provided for students at the baccalaureate, master's, specialist in education, and doctoral levels. JSU strives to provide educational activities that will prepare students to choose learning experiences; to initiate careers; and to contribute to the social, cultural, and economic development of the state, nation, and the world.

The Ana C. Méndey. University System is the second-largest private university system in P'uerto Rico. Its mission is to expand post-secondary education opportunities for thousands of Puerto Rican youths who lack access to higher education and to attract students with high potential who, because of their cultural and economic

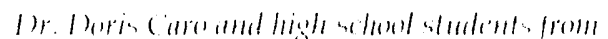
Ihe I Mle Irogeram in Ille Metropulitum

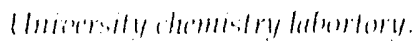


background, would otherwise be denied a college education. AGMUS believes that if significant numbers of Hispanics are to participate successfully in scientific and technical fields, they must receive quality education in these subjects. To achieve this goal, AGMUS administers and directs two universities and a college, with a combined enrollment of over 17,500. Metropolitan University (UMET) and Eastern University College (CUE), each with an enrollment of 5,000, are located in the greater San Juan area. Turabo University (UT), with 7,500 students, is in Gurabo, in the interior of the island. The universities offer bachelor's degrees in a number of disciplines and a master's degree in Business Administration. CUE

Nere science resentch building at Metropolitan University. offers transfer programs in all majors as well as a broad technical program in health fields. It is expanding from its roots as Puerto Rico Junior College toward offering four-year curricula.

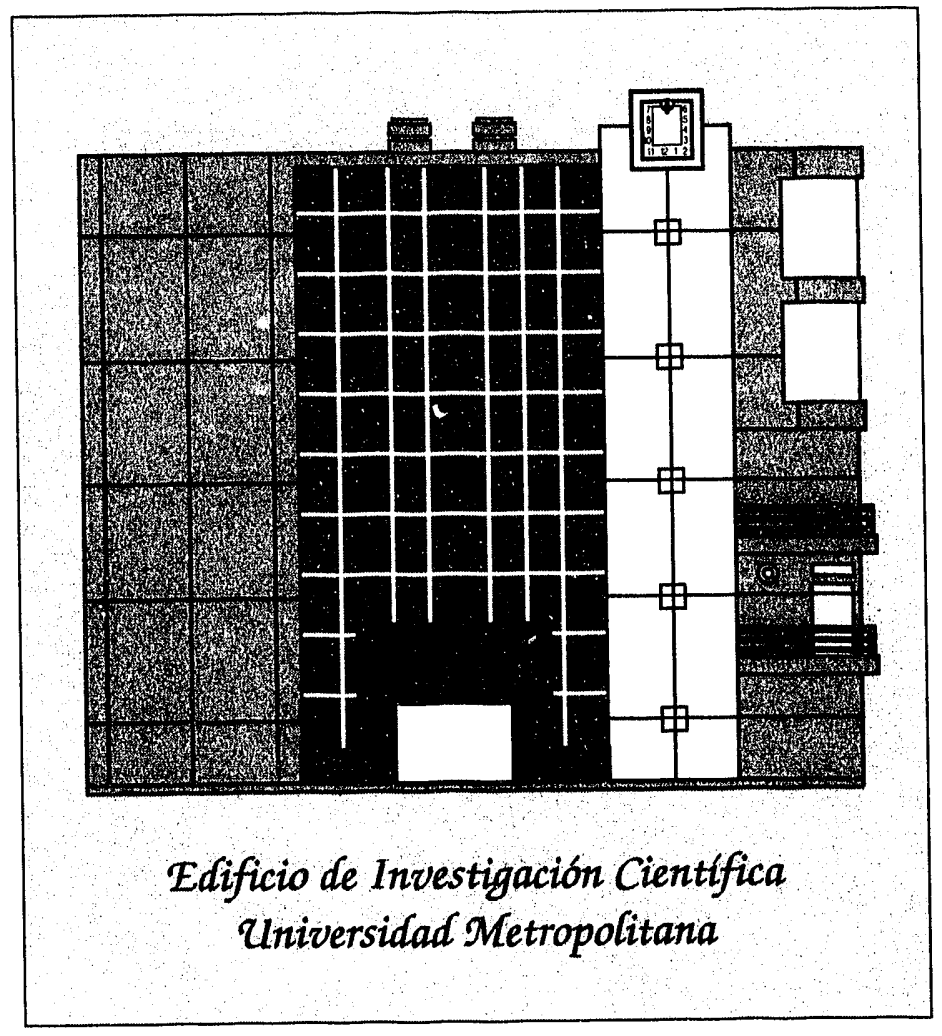

4 LBL//SU/AGMUS Science Consortium Annual Report 


\section{STUDENT DEVELOPMENT}

oal: To increase the number and

quality of JSU and AGMUS

mathematics, science, engineering, and technology students who are pursuing

graduate degrees or energy-related careers.

-67 students participated in research at their home campuses.

- 38 students received research internships at LBL.

-24 studerts were involved in collaborative research sponsored by the Science Consortium.

The student development program of the Science Consortium is largely focused on student involvement in research activities, both on campus and at LBL. Overall, 77 students participated in research at either their home universities or LBL during FY 1991, and 79 participated during FY 1992.

The outstanding students who are selected for the LBL research-participation programs have usually had preparation through on-campus research sponsored by the Science Consortium. The experience of a semester or summer spent working in a research group allows the students to comprehend the processes of, 


\section{STUDENT DEVELOPMENT}

and participate in, "doing science."

When possible, return appointments

at $\mathrm{LBL}$ are made available to the

students. This additional intense

research activity not only continues to

strengthen their skills and knowledge in the areas of their research, but

further prepares them for graduate school.

Several LBL student interns began

graduate studies at non-Science

Consortium universities during FY

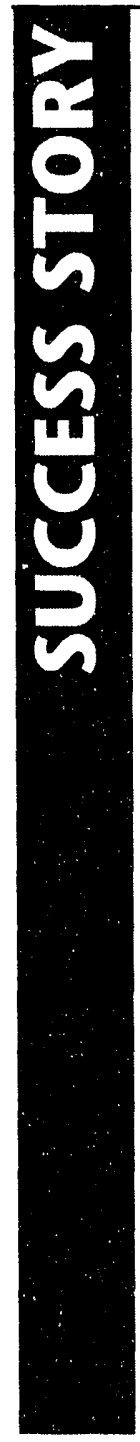

Jeannette Gomez faced considerable odds in pursuing a degree in chemistry at Turabo University. While enrolled at the university, she married and had a daughter. She took a part-time job to make ends meet. It was difficult to reconcile family demands with the fulfillment of her educational goals, but jeannette persisted.

When presented with the opportunity to come to Berkeley, Jeannette seized it enthusiastically. Her first project at LBL concerned a chemical process for removing pollutant gases from smokestacks. In this project she first realized that she could build upon her chemistry background to pursue an exciting research career in environmental science. Her next endeayor at LBL was a biological project in environmental science, in which she characterized the adverse effects of cigarette smoke on hemoglobin and myoglobin. She became skilled in the use of a variety of sophisticated instruments in a remarkably short time. Her contribution to the project was sufficient to warrant her inclusion as a co-author and presenter of the work at an important research conference. She became very interested in hemoglobin and soon acquired detailed knowledge about its structure and function, reading textbooks and selected papers from the literature, not only in the lat oratory but also on her own time.

She continued to overcome considerable challenges, including the questioning of her priorities by friends and family and the dissolution of her marriage. She remained steadfast in her commitment to her daughter and her career. The strength of her commitment enabled her to be unusually productive in her research efforts. Her experiments were instrumental in bringing the cigarette smoke research to a publishable stage. The work, co-authored by Jeannette, has recently been published in the peer-review journal Free Radical Research Communications. Co-authorship of journal publications by undergraduate students is rare, and this accomplishment is a measure of Jeannette's exceptional success at LBL. Currently Jeannette is enrolled in the graduate program at the School of Public Health at Pittsburgh University, where she has joined a group investigating mechanisms of carcinogenesis.

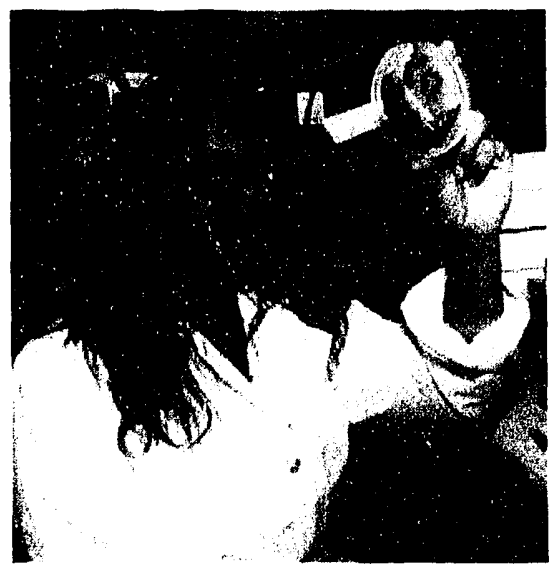




\section{STUDENT DEVELOPMENT}

1991 and 1992. Stephen Ekunwe, with an M.S. degree in biology from JSU, entered a doctoral program in molecular biology at Michigan State University. Jeannette Gomez, a chemistry graduate of UT who participated in four internship appointments at LBL, started her doctoral studies at the University of Pittsburgh, where she was joined by Susanna Felix, a UT classmate and LBL summer intern from FY 1990 and 1991. UT chemistry graduates Sandra Gonzalez and Ruth Otero both entered graduate studies at the University of Puerto Rico's Rio Piedras campus, with an agreement that their graduate research would be under the direction of UT Professor Edgard Resto.

During FY 1991 and 1992, 38 students participated in 49 semester or summer internships. Ten of these students were working as part of the Collaborative Research program, carrying out research at LBL that directly links with research being conducted on their home campuses.

Jeannette Gomez, a chemistry student from UT, worked with Rolf Mehlhorn on the "Bioassay of Environmental Toxins" project. Biology graduate student Jesus Loya and undergraduate chemistry major

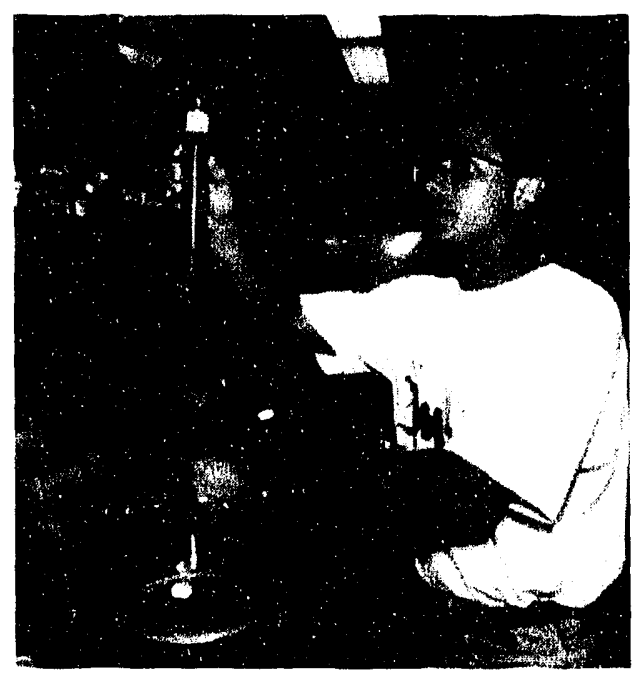

Ricurfor Pirez, a bioloses student from Metropolitan Lmioresity, working at LC/LBL on

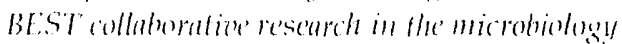
laboratory. 


\section{STUDENT DEVELOPMENT}

Mishi Pugh, both from JSU, and undergraduate biology major Andrés Polanco from UMET continued their work with LBL's Dale Perry, JSU professor Huey-Min Hwang, and UMET Professor Luis Feliu on the "Chemistry of Toxic Organic/Metal Ion Co-Contaminants and Their Effects on Microbial Communities" project. JSU students Stephen Ekunwe, Rondy Epting, and April York, along with AGMUS students Sandra Gonzalez, Ruth Otero, and Ricardo Perez, worked with Professors Wen-Hsun Yang (JSU) and Edgard Resto (UT) and LBL researchers Bob Buchanan, Terry Leighton, and Andy Yee on the "Bioremediation Education, Science

Jackson State student Charlic Clay discussing his work with students and LBL ataff at the L.BL. summer poster session. and Technology" (BEST) program, an extension of the highly successful 1991 Summer Research Campaign.

Other student internships at LBL were spread over nine research and resource (support) divisions, and included such diverse tasks as assisting in the sequencing of the human genome, modeling the physics of the atmosphere, supporting particle accelerator experiments, and helping to ensure that the LBL working environment meets all relevant standards.

The summers are the most concentrated period for research internships at LBL, with 19 students on-site in 1991 and 22 students conducting research in 1992.

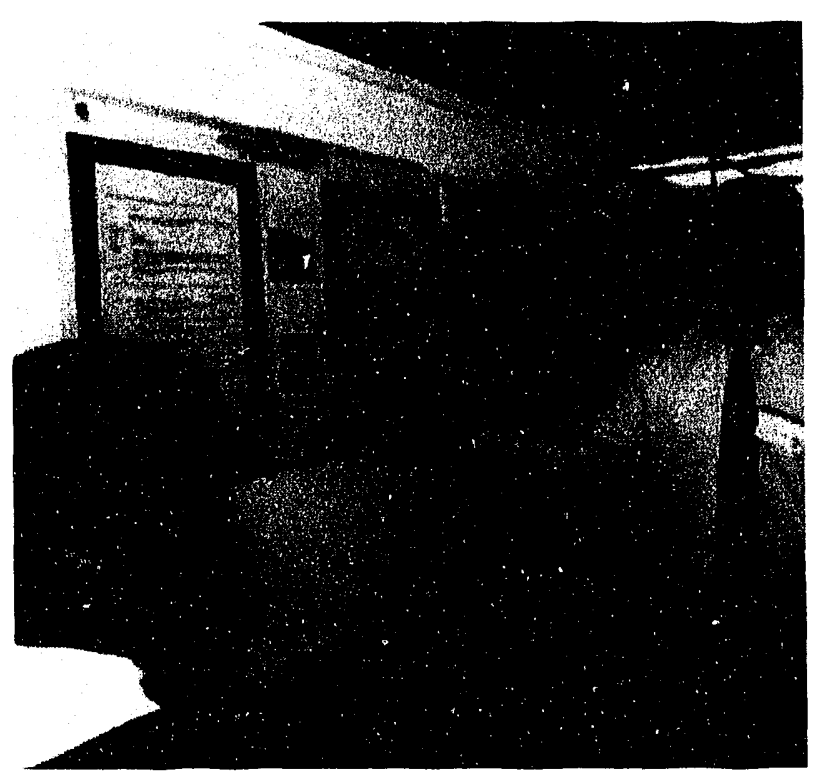




\section{PRECOLLEGE}

oal: To increase the number of freshman at AGMUS and JSU with the potential for attaining graduate degrees or careers in energy science, engineering, or technology.

- AGMUS extended its involvement in precollege programs, targeting high school science teachers and students with potential to graduate in science from AGMUS universities.

- JSU has taken on a leadership role in Mississippi with local and regional school districts, providing summer support for nine teachers and 52 students.

- Seven teachers from high schools in Puerto Rico and Mississippi joined DOE Teacher Research Associates for an eight-week summer program.

- The Science Consortium Precollege Task Force provides an arena for mutual technical assistance to establish quality projects and activities.

While each of the institutions has its

own active precollege program,

representatives of those individual

programs met as the Science Consortium

Precollege Task Force to exchange

information on their programs and to

identify areas in which the Science

Consortium partners could work together

to make programs more effective. A report 


\section{PRECOLLEGE}

was issued in July 1992 that presented a precollege program blueprint for the Science Consortium.

JSU has initiated an on-campus summer program for high school students to provide enrichment activities focusing on computer literacy, mathematics, and communication skills, in addition to various science-related topics. In the summer of 1991, 25 students, three teachers, and two undergraduate counselors participated in the program. The 1992 summer program added another class of 27 students to the 25 returning from 1991, for a total of 52 students, six instructors and four undergraduate counselors. Each summer, field trips for the students included Aquarium of the Americas in New Orleans and the Stennis Space Center.

In addition to these programs, JSU's precollege outreach has expanded significantly during 1991 and 1992 with support from the National Science Foundation, other DOE national laboratories, and federal and state departments of education. Over 400 precollege students and 50 teachers participated in on-campus summer mathematics and science workshops in 1992.
Building on the strong base of the CAUSA program for gifted high school students that AGMUS has operated for several years, two new AGMUS precollege programs were established with Science Consortium sponsorship.

- Updating the knowledge base in chemistry and biology for high school science teachers was the focus of workshops held at UMET and UT. In 1991, 175 teachers participated in the workshops.

- EMEC, an enrichment and preparation program for high school seniors with potential to succeed in science, was initiated at UMET, with emphasis on oral English as well as mathematics and science. The matriculation rate for the student participants into AGMUS

universities ias increased during the three years of the program.

Eighteen students from this program,

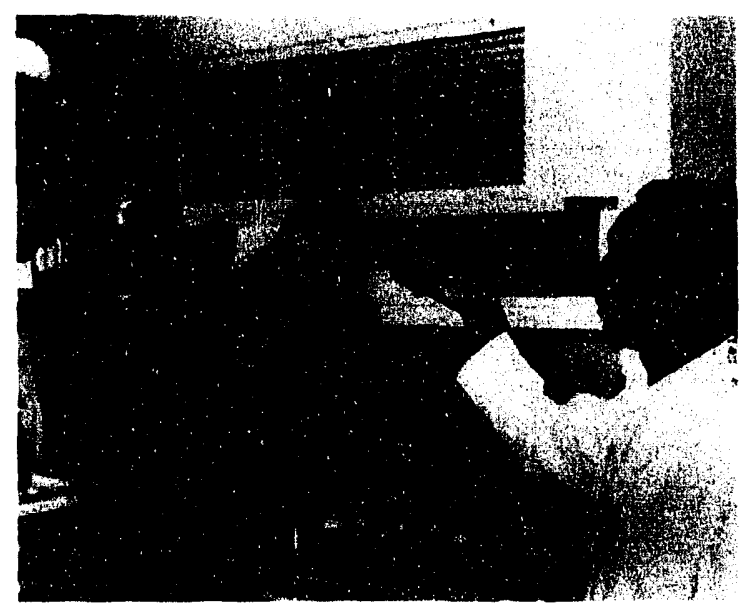

High school stuternt Cletincth Loutsille zerking in aquatic toxicology will lackson State marime biolegist Dr. fomathum Wilsom. 
representing $40 \%$ of the $1991 / 92$ participating seniors, enrolled at UT, UMET, or CUE for the 1992/93 academic year, up from 11 students (31\%), and 15 students $(36 \%)$ in the first two years, respectively. Most of the other students from this program are pursuing technical degrees at other Puerto Rican colleges and universities.

Encouraging and preparing students to enter JSU or the AGMUS universities with the skills and desire necessary to complete an undergraduate degree in science or mathematics, and to ther continue their education into graduate school is a function that must be local in focus. Teachers can be empowered to become active participants in this

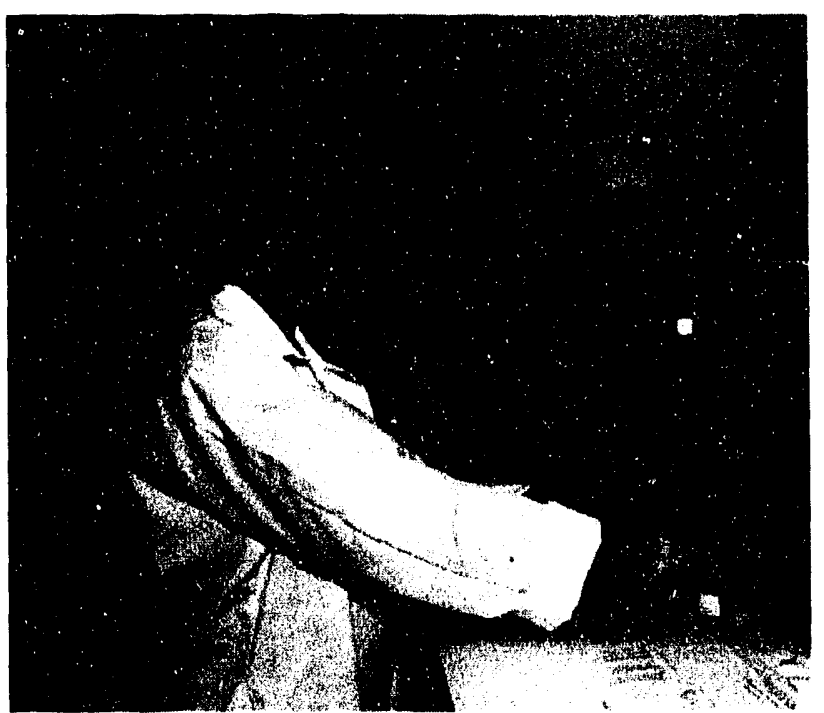

enhancement process through their own involvement in scientific research. The DOE Teacher Research Associates (TRAC) program has proven to be highly effective at this empowerment process. During the summers of 1991 and 1992, four teachers from Mississippi and three from Puerto Rico, all from high schools that produce graduates from which JSU and AGMUS universities draw, participated in the TRAC program at LBL with teachers from across the nation. As teacher research associates, they became members of scientific groups and developed skills and activities that could be taken back to their classes.

Direct involvement of precollege students comes through the DOE's High School Honors program. At LBL, this program included students selected from high schools in Mississippi and Puerto Rico with assistance from JSU and AGMUS. Four students in 1991 and three in 1992 joined groups of nearly 60 students from every state to study recombinant biology for two weeks at LBL.

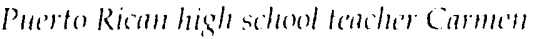
Ily/und aroking on the symthe'sis of

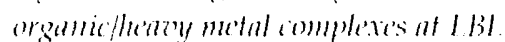


- Science Consortium faculty members presented 49 papers at seminars, conferences, and professional meetings.

- 13 JSU and AGMUS faculty members were supported for summer research at LBL.

Eight faculty members from JSU and

five from AGMUS participated in research at LBL during the summers of 1991 and 1992. JSU physics professor Floyd James explored magnetic properties with Paul Berdahl of the LBL Energy and Environment Division. Kunquan Sun of JSU's Industrial Technology Department worked with Gareth Thomas of LBL's Chemical Sciences Division. Wen-Hsun Yang from JSU's Biology Department and Edgard Resto, a chemist from UT, worked on the BEST collaborative research project with scientists and faculty from LBL's Earth Sciences and Energy and Environment Divisions and two departments from UCB. Yi-Chuan Pan of JSU worked with LBL Information and 


\section{FACULTY DEVELOPMENT}

\author{
Computing Sciences Division \\ researcher Bill Johnston. Huey-Min \\ Hwang of JSU's Biology Department \\ and chemist Luis Feliú of UMET \\ worked with Dale Perry from LBL's \\ Earth Sciences Division on the
}

\author{
"Chemistry of Toxic Organic/Metal \\ Ion Co-Contaminants and Their \\ Effects on Microbial Communities." \\ This is a collaborative research projec ${ }^{4}$ \\ to characterize metal-organic \\ compounds that are present as
}

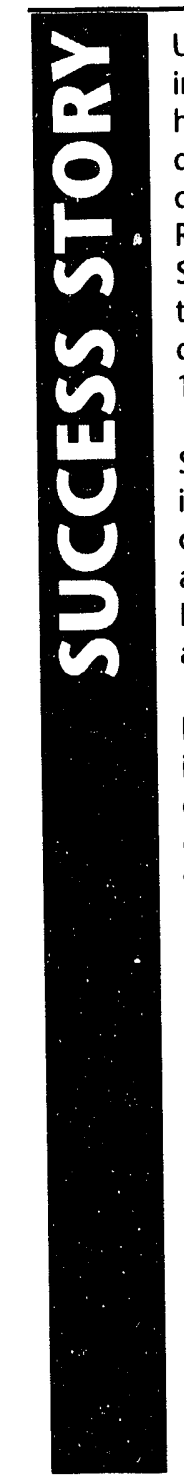

UMET chemistry professor Luis Feliú has returned to research and student mentoring with an enthusiasm that characterizes the dedicated college teacher. Following his first summer research experience at LBL in 1988, Luis returned to UMET with a determination to establish a research project to study the suitablity of the polycyclic aromatic hydrocarbon composition in the atmospheric particles in Puerto Rico as a marker for mobile source (automobile) contribution to air pollution. Students were actively involved with "hands-on" activities from the very start of this project, and they continue to carry much of the research load. A paper describing the atmospheric particle research was selected to be highlighted at the 1992 Spring Meeting of the American Chemical Society in the Sci-Mix Reception.

In the summer of 1990, Luis and one of his students were participants in the Summer Research Campaign at JSU, studying the Chemistry of Toxic Organic/Metal lon Co-Contaminants with biology professor Huey-Min Hwang of JSU and chemist Dale Perry of LBL. The summer results were exciting, and the project was awarded a Collaborative Research grant to continue. On their return to Puerto Rico, Luis and his student assistant, Andrés Polanco, began preparations to be active collaborators, focusing on the synthesis of new model compounds for study.

Luis brought this work to the attention of Dr. José Centeno of the Armed Forces Institute for Pathology in Maryland, and the collaboration was extended to include Dr. Centeno as an active participant. Their research continues to produce conference presentations and refereed publications, and has led Dr. Centeno's laboratory to donate an atomic absorption spectrometer to UMET. This spectrometer will facilitate the expansion of the work on campus in Río Piedras, where active student involvement can continue to be a primary function of the research.

Luis is Currently Director of the Science Consortium for AGMUS, but is able to continue his teaching and research interests. His re-entry into research with collaborators such as Dale Perry and José Centeno has allowed him to discover in himself outstanding talents as both a researcher of national rank and a mentor for future scientists.

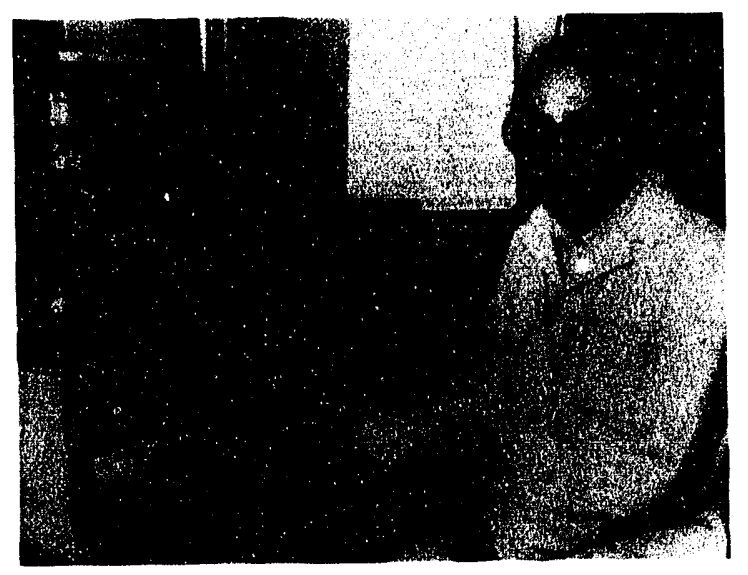




\section{FACULTY DEVELOPMENT}

hazardous contaminants in the environment. Biologists Carmen Reveron from CUE, Ana T. Méndez from UMET, and Jonathan Wilson from JSU conducted collaborative research with physicist Rolf Mehlhorn of LBL's Energy and Environment Division on the "Bioassay of Environmental Toxins" project. Keith Johnson, a meteorologist from JSU, worked with LBL Energy and Environment Division scientist Ron Ritschard on global climate effects. Charlie Gaulden from JSU's Industrial

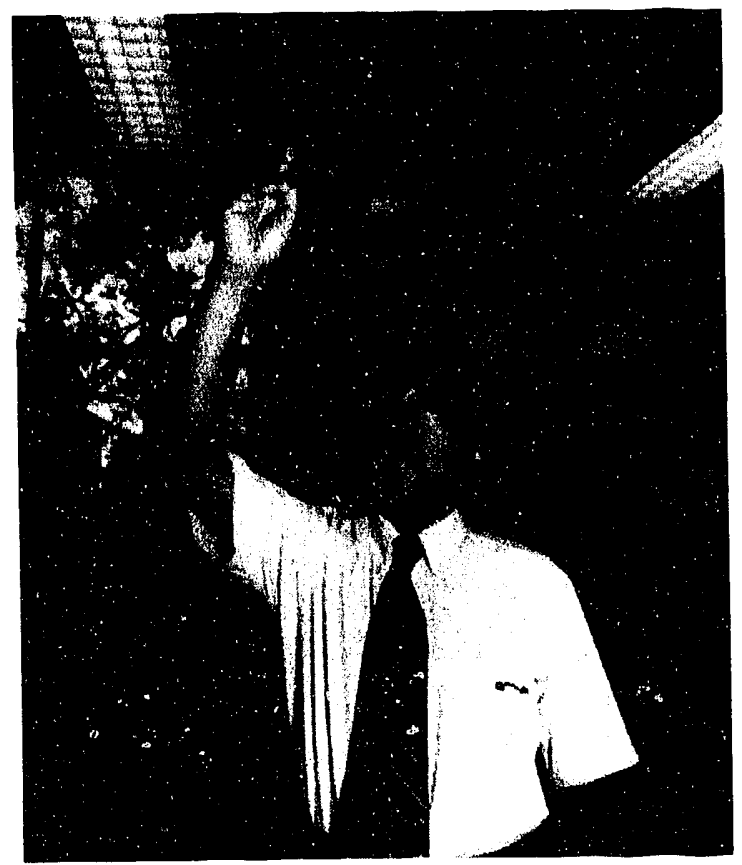

Technology Department worked with the Chemical Education for Public Understanding Project (CEPUP) at the Lawrence Hall of Science to adapt CEPUP curriculum modules for use in the JSU Industrial Technology Program. Carlos Candelario from the Business Technology Program at CUE worked with Allan Konrad and Ted Sopher of the LBL Information and Computing Sciences Division on the operation of computer networks.

AGMUS has continued to encourage faculty members to pursue Ph.D. degrees. UMET Professor Margarita Irizarry is nearing the completion of her Ph.D. degree in molecular biology at the University of
Inckon State Unieresity microbiolegy professor Dr. WonHsun Yang, a key participant in the summer rescarch comprignt, in the laboratory at L.BL. 


\section{FACULTY DEVELOPMENT}

\author{
Puerto Rico, and Luis Arana is \\ completing his Ph.D. degree in \\ mathematics at New Mexico State \\ University. Ramon Alejandro and \\ collaborative research participant Ana \\ T. Méndez started their doctoral \\ studies in FY 1991. \\ Science Consortium faculty
}

\author{
members presented 49 different \\ papers at various seminars, \\ conferences, and professional \\ meetings in FY 1991 and 1992. A total \\ of 27 papers were accepted for \\ publication, 26 by JSU faculty \\ members and one by AGMUS faculty \\ members.
}

Dr. Kunal Ghosh was a relatively new member of the Jackson State Physics Faculty when he came to LBL for a summer research appointment in 1991. For Kunal, this was a transforming experience. He joined Dr. Jane Long and her group studying fluid-flow in porous rock media. Kunal had a strong interest in combining fractal analysis and new statistical methods for modeling underground systems. His work with the LBL group was highly successful and led to two publications and three presentations the following year. While his research at LBL. was clearly successful and provided Kunal with support and recognition for his talents and abilities, it was not the transforming experience. This came about when he had the opportunity to see the LBL Center for Science and Engineering Education in action. The empowerment that comes from developing and managing partnerships and the additional resources these partnerships bring was immediately evident to Kunal. He immediately became a student of the partnership strategy.

Upon returning to Jackson State University, his enthusiasm and belief in the possibility for change led to his appointment as Physics Department Chair. In the last two years, the Physics Department has expanded from eight to forty majors and the size of the Faculty has doubled. In addition, Kunal established a recognized statewide effort for science education reform and became the director of the Mississippi Science Partnership, with a vision for improving the teaching and learning of mathematics and science in the public schools in that state. The unleashing of Kunal's leadership abilities, which has led to these improvements in the JSU Physics Department, the Mississippi Science Partnership, and many other benefits to students in Mississippi, is a direct consequence of one summer visit to LBL. He is happy to acknowledge this fact. 
- Intensive collaborative summer research on the BEST program continued for the second summer, leading to a proposal to establish Centers of Excellence in bioremediation education and research at $\mathrm{LBL} / \mathrm{UCB}, \mathrm{JSU}$, and AGMUS.

- Equipment was donated to AGMUS by the Department of Defense as a result of "Toxic Organic/Metal Ion Co-Contaminants" collaborative research.

- A poster presentation by Luis Feliú and Andrés Polanco at the 1992 Spring Meeting of the American Chemical Society in San Francisco was honored at the Sci-Mix reception.

The primary strategy is to strengthen the mathematics, science, and technology education capabilities of JSU and AGMUS through collaborative research projects. The most recent of these collaborative efforts, the BEST project, is based on the highly successful 1991 and 1992 Summer Research Campaigns. This project is in its first year of funding. The research has already generated a paper, which was presented at the Fifth International Symposium on Selenium in Biology and Medicine in July 1992. This education and 


\section{RESEARCH}

research project led directly to a Memorandum of Understanding among the Science Consortium Partners and UCB's School of Natural Resources to establish Centers of Excellence at UCB/LBL and JSU, with a third center to be established at AGMUS in following years. Based on the significance of the research resilts and the potential for enabling JSU $I$ and AGMUS to take a leading role in education and research in this cuttingedge field, it is likely that BEST will become a major contributor to the field of bioremediation and will lead in the education of underrepresented professionals in the field.

The BEST Centers will be a systemic and comprehensive extension of the Science Consortium collaboration with UCB. These centers will implement a multi-site integrated

Turalo University chemistry students Ruth Otero and Santira Gonzalez studying biore'mediation with LBL scientist and LIC pathology professor Dr. Bob Buchanan and Turabo chemistry profe'ssor Dr. Edgard Resto as part of the BEST collaboratize rescarch.

program designed to leverage existing bioremediation resources and disseminate bioremediation educational resources, cutting-edge research, and advanced technologies. The research will be carried out collaboratively with faculty and students from historically Black colleges and universities (HBCUs) and minority institutions (MIs) around the country. Students will be offered secure pathways to undergraduate and graduate degrees in the field. A proposal to the U.S. Department of Defense is in preparation to fund the establishment and operation of these

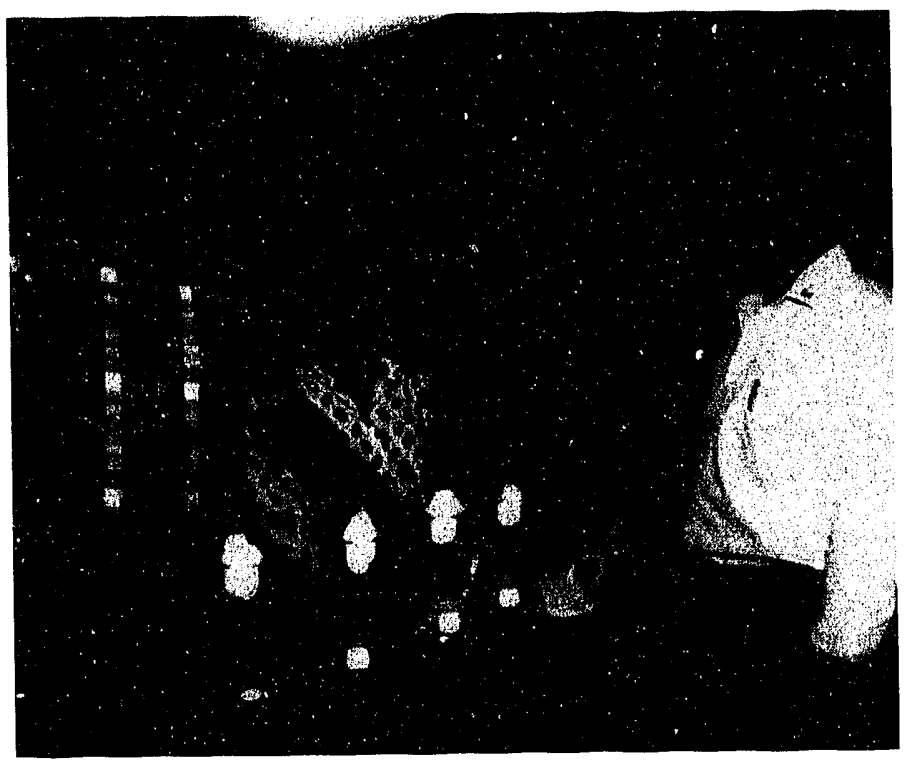




\section{RESEARCH}

centers at a multimil'ion dollar annual level.

The "Chemistry of Toxic Organic/Metal Ion Co-Contaminants and Their Effects on Microbial Communities" project is finishing its second year, with several conference presentations by the investigators and students working on the project.

Unique and potentially important crystal structures have been determined for several metal-organic complexes. Several papers have been prepared, and two have been accepted for publication. Dr. José Centeno of the Armed Forces Institute of
Pathology in Maryland donated an atomic absorption spectrometer to AGMUS to enable Dr. Feliú to expand his research. A proposal is in preparation, in collaboration with Dr. Centeno, for continuation and extension of this work.

Individual research begun by Luis Feliú into the separation and identification of polycyclic aromatic hydrocarbons in atmospheric particulate material in Puerto Rico led to a conference presentation that was selected as exemplary by the American Chemical Society and was highlighted at the SciMix reception during the spring 1992
Signimg of the BLST Menorandum of Umlerstanding by Jackson State Lmionsity l'resident Dr. Ilerman Smill, ACMLIS President Mr. Fosé Méndez, LIC Berkeley Natural Resonurces Dean Dr. Wilford Garduer, and L.BL. Associate Laboratory Director D. r. Martha Krols.

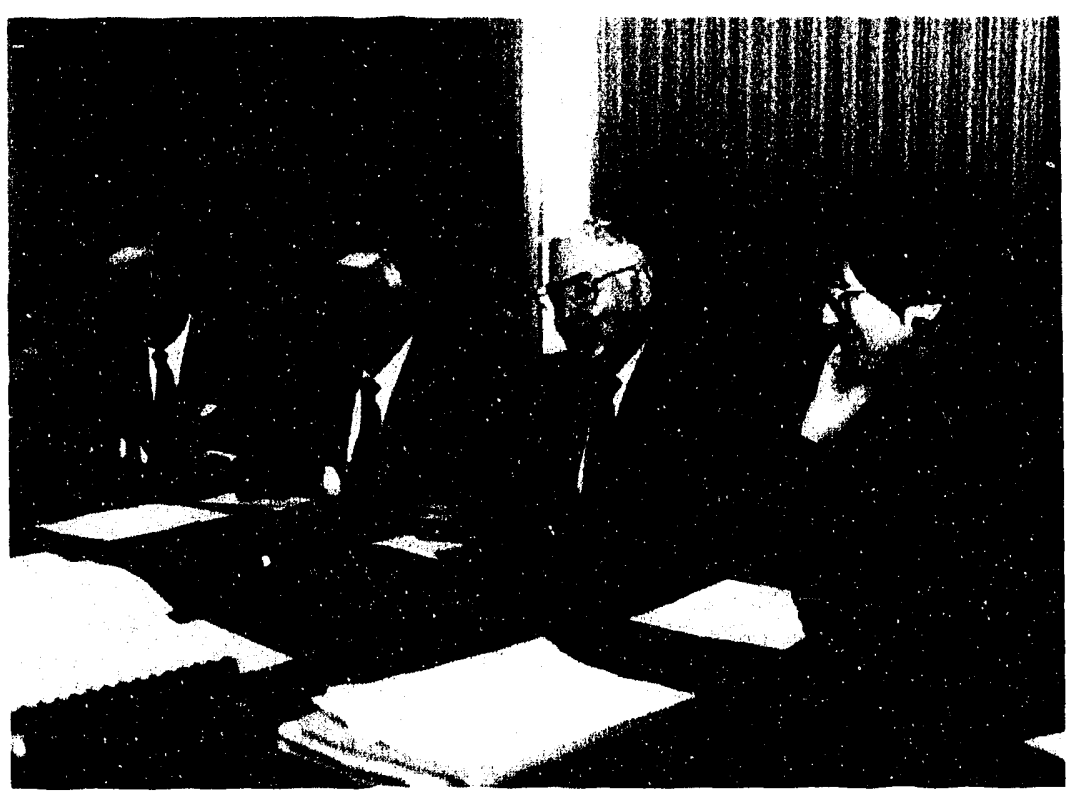


meeting in San Francisco. This work, largely conducted by undergraduate chemistry students, had its origins in an earlier summer visit by Professor Feliú to LBL.

The first three collaborative research projects to be funded have received transition funding to allow the investigators time to apply for and receive grants from other agencies:

- The "Joint Laboratory for Information Research and Technology" project has demonstrated the capability to access remote computer databases in a "seamless" manner, requiring little or no hardware or software knowledge of the user. Work continues on the development of curriculum information that will be available for access by this technique.

This project has had significant results in accelerating the extension of computer networking capabilities to include external connectivity at JSU and AGMUS.

- The "Computer Database and Models for Human Hemoglobin Genes and Their Functions" project has achieved most of its goals, and work has been largely transferred to JSU and AGMUS. Prospects are good for continuation of this project through joint proposals between JSU and the University of Mississippi Medical School.

- The "Bioassay of Environmental Toxins" project has explored a variety of biomarkers and reported the initial results in a paper presented at the Second International Energy Conference for the Americas. Two journal papers, based in part on this collaborative research, have been submitted for publication.

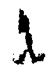




\section{SEMINAR, LECTURE, AND CONFERENCE SERIES}

oal: To provide an ongoing forum

for forefront science and technology for students and faculty at JSU and AGMUS.

- An annual Energy Research Conference was held in San Juan, Puerto Rico.

- A short course in Groundwater Hydrology was presented by LBL scientists in Puerto Rico.

- Lectures and seminars were presented at JSU and AGMUS universities.

An ongoing exchange of staff to JSU

and AGMUS from LBL provides the opportunity for students and faculty to present their research interests and to discuss current trends and critical issues in energy science and technology.

An Energy Research Conference was held on September 25-26, 1991, in San Juan, Puerto Rico, in conjunction with the Second Pan American Congress for Energy and Chemistry for the Americas. The focus of the conference was "Partnerships for Diversity in EnergyRelated Careers." Participation in the conference by representatives of other minority-university partnerships with 


\section{SEMINAR, LECTURE AND CONFERENCE SERIES}

national laboratories offered an opportunity for sharing successful strategies.

"Applied Groundwater Hydrology" was the subject of a short course presented by LBL Earth Sciences Division scientists Marcelo Lippmann and Iraj Javandel in June 1991 at the University of Turabo. Students and faculty of the AGMUS unversities, as well as invited members of the technical community in Puerto Rico, learned in depth about this field and its importance to understanding the spread of environmental pollutants.

In March 1991, Tesfa Haile, computer science professor at JSU, presented a seminar entitled "Analysis of Solid Waste: An Alternative Approach to Energy" to AGMUS students and faculty at UMET and UT. The following November, Rick Schwarz of the LBL Life Sciences Division lectured to faculty and students at JSU and AGMUS universities on his biotechnology research at LBL. Kathleen Brennan, a research veterinarian at the Center for Functional Imaging in LBL's Life Sciences Division, delivered lectures on "Advanced Medical Imaging Techniques Used to Study Brain and Heart Diseases" at each of the AGMUS universities in March 1992. Dr. Brennan's lectures were well received by groups of $50-75$ students and faculty at each site.

In April 1992, the Science Consortium sponsored a workshop in San Juan, Puerto Rico, on Atmospheric Chemistry. The workshop, organized by LBL Atmospheric Aerosol Research head Tihomir Novakov, provided a forum for discussion between researchers at AGMUS and the University of Puerto Rico and some of the nation's leading figures in atmospheric chemistry. Featured lectures were by Dr. Yoran Kaufman (NASA/Goddard Space Flight Center), Prof. Dennis Lamb (Pennsylvania State University), and Dr. Joyce Penner (Lawrence Livermore National Laboratory). 
- JSU instituted a Ph.D. program in environmental science.

- Progress was made towards a chemistry major at UMET.

The Environmental Science Doctoral

Program, a new interdisciplinary program in the School of Science and Technology at JSU, was instituted in the fall semester of 1992. There are three objectives for the program:

- To contribute to the humanresource base in the field of environmental science.

- To conduct environment-related research.

- To make the public aware of the environment-related issues.

This new Ph.D. program, the first in the School of Science and Technology, positions JSU to offer an interdisciplinary doctoral degree to students matriculating in the more traditional scientific disciplines at JSU and elsewhere. 


\section{CURRICULUM DEVELOPMENT}

With the addition of courses in analytical chemistry, abstract algebra, and a third semester of calculus for the 1992/93 academic year, UMET moved closer to its goal of offering a degree in chemistry in 1994 . This progress positions UMET to take full advantage of the interdisciplinary approach that is a prominent feature of much of the Science Consortium's collaborative research.

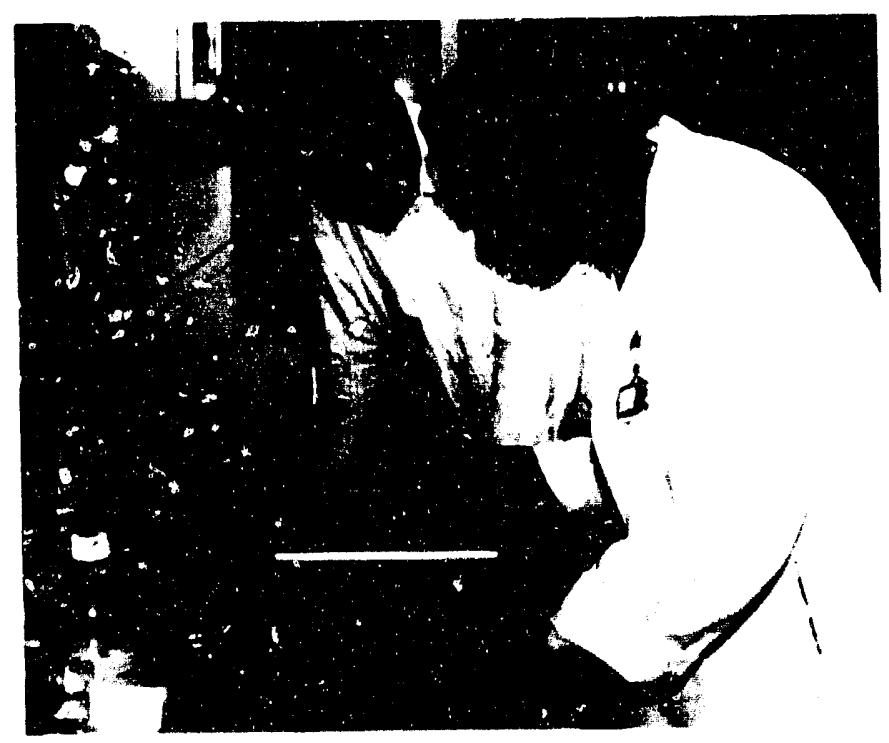

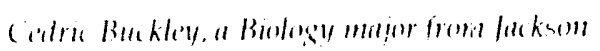
State lluareratly forst partic ifuted in the

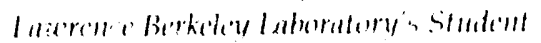

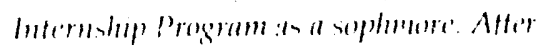

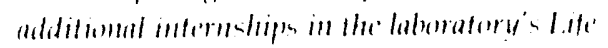

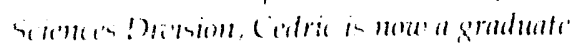

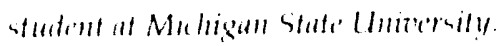




\section{MANAGEMENT AND INFRASTRUCTURE DEVELOPMENT}

oal: To manage and leverage
resources to maximize the Science
Consortium impact on the mathematics,
science, technology, and engineering
student pipeline.

- A three-year plan was prepared to define and broaden the focus of the Science Consortium through outreach to other institutions and partnerships.

- Internet "connectivity" was achieved at JSU and AGMUS institutions.

In the spring of 1992, a summary

report and three-year plan were prepared

to chart a course for increasing outreach to other minority institutions and for obtaining alternate funding to reduce support from the DOE.

LBL provided assistance to JSU and AGMUS in the areas of regulatory compliance and purchasing.

JSU and AGMUS, working with LBL Information and Computing Sciences Division personnel, achieved "connectivity" with the Internet system. This effort enables electronic communication among the Consortium partners and with research and education institutions throughout the nation. This 


\section{MANAGEMENT AND INFRASTRUCTURE DEVELOPMENT}

achievement was brought about

sooner than anticipated, in part

through impetus provided by the

"Joint Laboratory for Information

Research and Technology"

collaborative research project. 


\title{
EVALUATION AND DISSEMINATION
}

\author{
oal: To provide an internal and \\ external assessment of the \\ programmatic components of the Science \\ Consortium and to make the benefits of \\ the DOE investment in the Science \\ Consortium and the experience gained \\ from that investment available to other \\ universities, federal agencies, and \\ partnerships.
}

- Program evaluations were conducted through participant questionnaires.

- Collaborative research was identified as an effective method of building education capabilities of JSU and AGMUS.

Since 1982, over 150 students have participated in over 200 placements at LBL. A participant questionnaire has been sent to students who held summer or academic term appointments at LBL throughout the life of the Science Consortium. Most of the questions were patterned after a DOE survey of participants in undergraduate student research programs conducted at various national laboratories. We expect thereby to be ultimately able to compare the responses of participants in the Science 


\section{EVALUATION AND DISSEMINATION}

Consortium student programs with those of participants in the other programs.

Two broad categories of information are covered in the questionnaire: 1) that related to the students while participating in the program, and 2) that related to their subsequent academic and professional careers. The information we have on the first category is largely complete and significant. Data for the second category are not complete, and efforts are being made to elicit a larger, statistically significant response.

The Science Consortium Advisory Committee convened to review program progress and provide

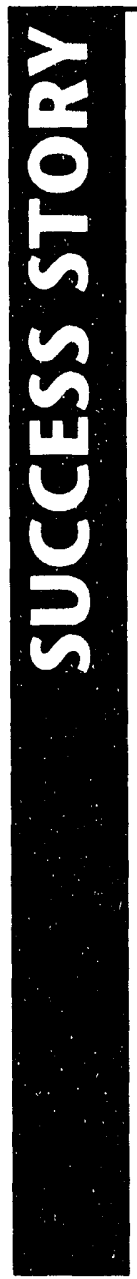

Stephen Ekunwe was a graduate student at Jackson State University when he first participated in the LBL Student Research Program. In the summer of 1989, he worked in LBL's Cell and Molecular Biology Division with Dr. Tracy Yang on the "Characterization of Growth Variants of Human Mammary Epithelial Cells." At JSU, he continued working with Dr. Wen-Hsun Yang, his faculty advisor, and in the summer of 1990, Stephen and Dr. Yang returned to LBL as one of the Consortium's first faculty/student research teams. They worked with Prof. Terrance Leighton of UCB on bioengineering the postexponential phase of Bacillus subtilis.

Early on, Stephen expressed an interest in both research and teaching. After finishing his master's degree, and having confirmed his research interest both at ISU and LBL, Stephen chose to test his teaching ability as a biology instructor at Tougaloo College in Mississippi, while continuing to hone his research skills in preparation for study for a Ph.D. degree in molecular biology.

He returned to LBL in the summers of 1991 and 1992 to continue his work with Profs. Yang and Leighton, contributing significantly to the development of the BEST research centers. In 1992, he brought Shunté Jones, a talented Tougaloo biology student, with him to work as part of the BEST team. Stephen began his doctoral studies at the end of this past summer and has spoken highly of the preparation he obtained through the Science Consortium programs. Stephen has expressed a strong interest in returning to teaching and research at an $\mathrm{HBCU}$ upon completion of his Ph.D. degree. We are confident that he will fulfill his interests by adding to the "science pipeline."

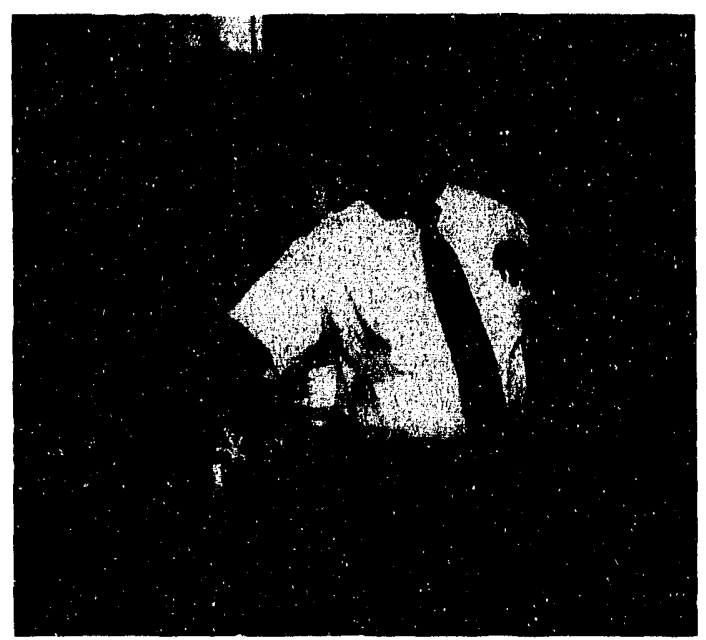




\section{EVALUATION AND DISSEMINATION}

recommendations for future

directions. As discussed earlier, collaborative research was identified as an effective method of building the mathematics, science, and technology education capabilities of JSU and AGMUS. An external evaluation of the collaborative research program and projects is planned for early FY 1993.

\begin{tabular}{lrrrrr} 
& \multicolumn{3}{c}{ Summary Budget } \\
& \multicolumn{3}{c}{ Expenditures by Program Area } & & \\
& \multicolumn{2}{c}{ FY 1991} & \multicolumn{2}{c}{ FY 1992} \\
Program Area & $\$, 000$ & $(\%)$ & $\$, 000$ & $(\%)$ \\
\hline Student Development & $\$ 588$ & $(22.4)$ & $\$ 545$ & $(21.8)$ \\
Faculty Development & 180 & $(6.9)$ & 113 & $(4.5)$ \\
Precollege Programs & 78 & $(3.0)$ & 105 & $(4.2)$ \\
Curriculum Development & 25 & $(1.0)$ & 21 & $(0.8)$ \\
Research & 866 & $(33.0)$ & 804 & $(32.2)$ \\
Seminars, Lectures, Conferences & 93 & $(3.5)$ & 71 & $(2.8)$ \\
Management \& Infrastructure & 774 & $(29.5)$ & 814 & $(32.6)$ \\
Evaluation \& Dissemination & 21 & $(0.8)$ & 26 & $(1.0)$ \\
Total & $\$ 2,625$ & $(100.0)$ & $\$ 2,499$ & $(100.0)$
\end{tabular}




\section{DISCLAIMER}

This document was prepared as an account of work sponsored by the United States Government. Neither the United States Government nor any agency thereof, nor the Regents of the University of California, nor any of their employees, makes any warranty, express or implied, or assumes any legal liability or responsibility for the accuracy, completeness, or usefulness of any information, apparatus, product, or process disclosed, or represents that its use would not infringe privately owned rights. Reference herein to any specific commercial products, process, or service by its trade name, trademark, manufacturer, or otherwise, does not necessarily constitute or imply its endorsement, recommendation, or favoring by the United States Government or any agency thereof, or The Regents of the University of California. The views and opinions of authors expressed herein do not necessarily state or reflect those of the United States Government or any agency thereof or the Regenis of the University of California and shall not be used for advertising or product endorsement purposes.

Lawrence Berkeley Laboratory is an equal opportunity employer. 

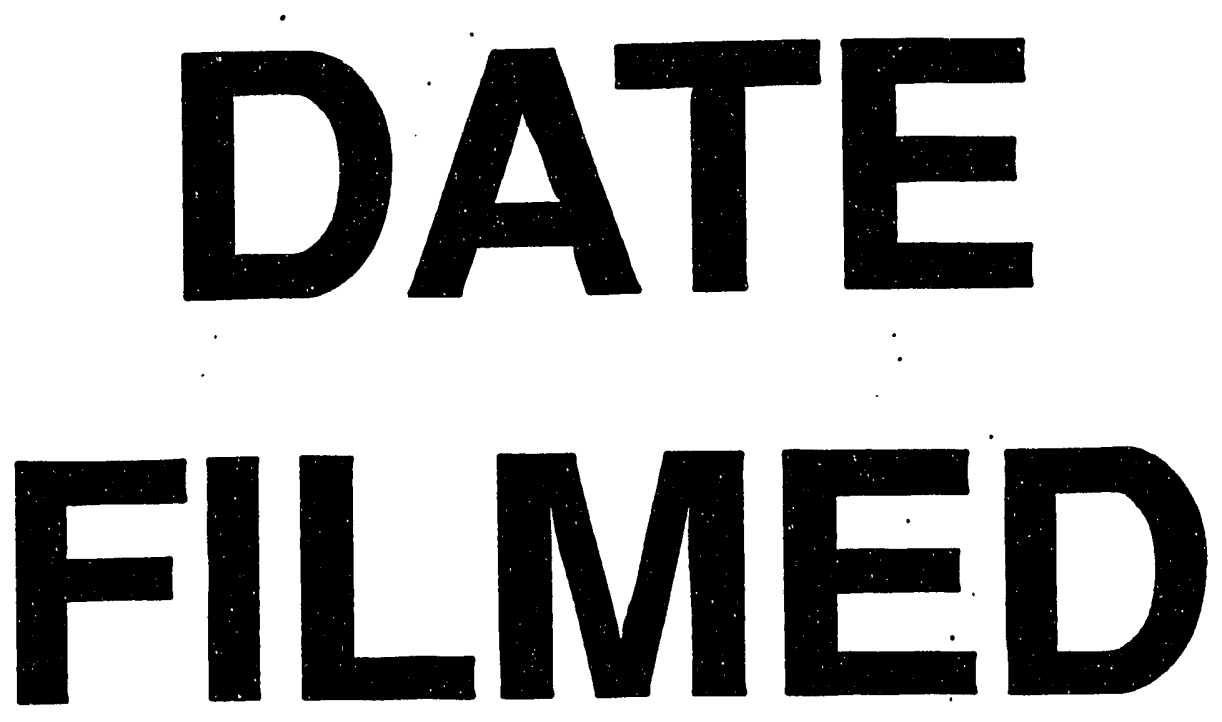

$10 / 12 / 93$
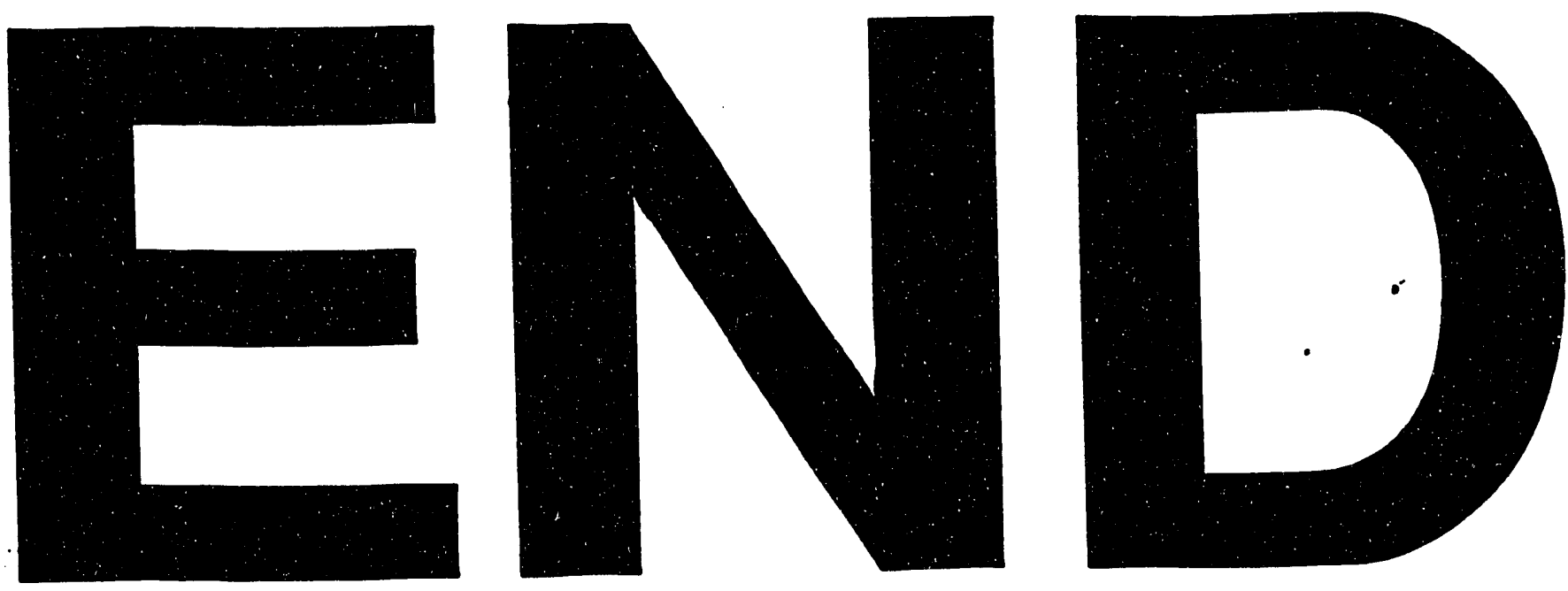
